\title{
Primary care reform and funding equity for mental health disorders in Ontario: a retrospective observational population-based study
}

\author{
Imaan Bayoumi MD MSc, Susan E. Schultz MA MSc, Richard H. Glazier MD MPH
}

Abstract

Background: Mental health disorders are associated with high morbidity and reduced life expectancy, and are largely managed in primary care. We sought to assess the equity of distribution of new alternative payment models and teams introduced under primary care reform in Ontario for patients with mental health disorders.

Methods: We conducted a retrospective observational study using population-level administrative data for insured Ontario adults (age $\geq 18 \mathrm{yr}$ ) to identify all primary care payments to physicians that were allocated to individual patients in 2002/03 and 2011/12. We identified patients with mental health disorders using validated algorithms, and modelled the relations between per capita primary care costs and mental health disorders over time, stratified by type of mental health or substance use disorder and type of primary care payment. In an adjusted model, we adjusted for age, sex, rurality, neighbourhood income quintile, immigrant status, comorbidity and primary care model. For comparative purposes, we also examined the distribution of primary care payments for people with diabetes mellitus.

Results: Total per capita primary care payments increased more slowly over the study period for patients with mental health disorders $(62.0 \%)$ than for the general population (88.3\%). Total payments for patients with substance use disorders increased by $142.7 \%$, largely owing to urine drug testing in opioid substitution clinics. Adjusted total payments for those with versus without mental health disorders decreased by $10 \%$ between $2002 / 03$ and $2011 / 12$, driven by lower alternative payments. Similar decreases, also driven by lower alternative payments, were found for all mental health disorder subgroups except substance use and for diabetes.

Interpretation: Payment and team reforms were associated with inequitable resource allocation to people with mental health disorders. The findings suggest the need for monitoring reforms for their impact on high-needs populations and making appropriate adjustments.

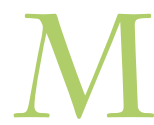

ental health and substance use disorders affect $33 \%$ of adults over their lifetime, ${ }^{1}$ and account for about $23 \%$ of years lived with a disability ${ }^{2}$ and a mortality gap of 13-20 years. ${ }^{3}$ Primary care physicians are the health care professionals most frequently consulted by adults with mental health disorders, ${ }^{4}$ but affected patients experience lower access and quality of primary care..$^{5-9}$

Strong primary care systems are associated with greater health equity and lower mortality and cost. ${ }^{10}$ An essential evidence-based attribute of effective primary care systems is equitable distribution of health care resources. ${ }^{11,12}$ In Canada, medically necessary physician and hospital services are universally funded for permanent residents without any direct charges to patients. In 2000, following a period of declining policy support for primary care, Ontario increased investment and implemented broad voluntary reforms in the delivery and payment of primary care aimed at improving access, quality of care and physician retention. ${ }^{13}$ Under the reforms, most physicians shifted from exclusive fee-for-service (FFS) remunera- tion to new models that incorporated blended capitation payments, patient enrolment, pay for performance and, in some cases, access to nonphysician health care professionals.

Previous work showed that fewer patients with mental health disorders than those without such disorders were enrolled in new payment models. ${ }^{14-16}$ However, little is known about the equity of distribution of new primary care investments, which we hypothesized would flow inequitably for adults with mental health disorders. We aimed to assess the equity of distribution of new alternative payments introduced under primary care reform in Ontario. For

Competing interests: None declared.

This article has been peer reviewed.

Correspondence to: Imaan Bayoumi, bayoumi@queensu.ca

CMAJ Open 2020. DOI:10.9778/cmajo.20190153 
comparative purposes, we also examined the distribution of primary care payments for people with diabetes mellitus.

\section{Methods}

\section{Design, setting and participants}

We conducted a retrospective observational study using population-level administrative data housed at ICES. Study participants included all adult (age $\geq 18 \mathrm{yr}$ ) Ontario residents eligible for universal health insurance and Ontario primary care physicians. Uninsured Ontario residents were excluded, as were physicians practising in Community Health Centres (representing $2 \%-3 \%$ of primary care provision ${ }^{17}$ ) owing to lack of payment data.

\section{Data sources and linkages}

The data sets used were the Registered Persons Database (a registry of all Ontario residents eligible for the Ontario Health Insurance Plan [OHIP]), the Corporate Provider Database (a registry of all providers and provider groups eligible to bill OHIP for their services) and the Client Agency Program Enrolment database (which lists all patients enrolled with a primary care physician within a primary care group). The data sets were linked by means of unique encoded identifiers.

Payment data sources, all from the Ontario Ministry of Health and Long-Term Care, were the OHIP database of FFS billings; the OHIP Architected Payments database of incentive, premium, bonus and capitation payments; the Generalized Alternative Payment Plan database of non-FFS payments to physicians who are part of alternative funding agreements; payments to academic health science centres; and a database of miscellaneous payments. The unique identifiers were used to link patients and payments, sometimes directly, sometimes via linkage between patients and physicians or groups. A detailed description of how payments to physicians and groups were allocated to patients is available in Appendix 1 (available at www.cmajopen.ca/content/8/2/E455/ suppl/DC1).

\section{Variable definition}

\section{Outcome}

We decided a priori that any payment to a primary care physician or a primary care enrolment model group would be deemed a primary care payment. Primary care physicians were defined as those whose specialty was listed as general practitioner or family physician, plus any physician with a fulltime affiliation with a primary care enrolment model (which included physician groups such as Family Health Groups, Comprehensive Care Models, Family Health Networks and Family Health Organizations, and multidisciplinary Family Health Teams).

We extended established patient-level costing methodol$\mathrm{ogy}^{18}$ to include payments specific to primary care reform. We included all payments for services provided to patients, plus payments to Family Health Teams for practice infrastructure and services of other health care professionals because these are important components of primary care reform. Only Ontario Ministry of Health and Long-Term Care payments were available and could be included. We allocated FFS payments to the patients for whom the service was provided. Block payments made to physicians or groups were divided among the patients assigned to the physician or group based on the type of payment and the relationship between the patient and the provider. A detailed description of the methodology used is available in Appendix 1.

Although some small pilot projects in 2002/03 used alternative funding models, payment data for these were unavailable, so all primary care payments in 2002/03 were FFS. We divided new primary care payments in 2011/12 (non-FFS payments, referred to collectively as alternative funding payments) into 4 categories: capitation, other physician payments (all noncapitation primary care payments to physicians), payments for interdisciplinary teams and other.

The study period was Apr. 1, 2002, to Mar. 31, 2012. We selected Mar. 31, 2012 as the study end date because interprofessional team payments were excluded from payment data sent to ICES after 2012.

\section{Exposure}

We identified people with mental health and substance use disorders using validated administrative case definitions (see Appendix 2, available at www.cmajopen.ca/content/8/2/E455/ suppl/DC1, for a complete list of diagnostic codes). ${ }^{19,20} \mathrm{We}$ stratified mental health and substance use disorders into 3 diagnostic categories: psychotic, nonpsychotic and substance use disorders. We identified people with diabetes using a validated administrative case definition. ${ }^{21}$

\section{Covariates}

We derived age, sex, rurality and immigration status from the Registered Persons Database. We measured rurality using the postal code and the Rurality Index for Ontario, with categories of urban (score 0-9), suburban (score 10-39) and rural (score $\geq 40$ ). ${ }^{22} \mathrm{We}$ derived neighbourhood income quintile using the postal code linked to census dissemination area. ${ }^{23}$ We identified recent immigrants as people who received an Ontario health card for the first time within the previous 10 years (about $75 \%$ of this group would be expected to be recent immigrants, and the remainder would be expected to have migrated from other Canadian provinces ${ }^{24}$ ). We used the Johns Hopkins Adjusted Clinical Groups System Version 10 to capture comorbidity according to Aggregated Diagnostic Groups. We determined primary care model type, including FFS, enhanced FFS (Family Health Groups and Comprehensive Care Model) and blended capitation (Family Health Organizations and Family Health Networks), using the Client Agency Program Enrolment database tables. ${ }^{13}$

\section{Statistical analysis}

We compared the population characteristics of people with various conditions to the Ontario population. Then we estimated the unadjusted per capita primary care payments for 
these groups in 2002/03 and 2011/12. Finally, we modelled the relation between per capita payments and the presence of a condition, controlling for prespecified covariates.

Before modelling, we found the distribution of per capita primary care payments to be highly skewed, which we addressed using a log-transformation. We then modelled the relation between the presence of a given condition and the $\log$ of per capita primary care payments, using ordinary least squares regression with log payments as the outcome, adjusting for prespecified covariates including age, sex, neighbourhood income quintile, rurality, immigration status, primary care payment model and comorbidity. We then exponentiated the modelling results to back transform them. The parameter estimate, when exponentiated, yielded an estimate of the ratio of the average per capita primary care payment for people with the condition compared to those without, controlling for the factors listed above. Exponentiating the least squares means plus half the mean square error produced adjusted cost estimates. $^{25}$

The unit of analysis in all models was the patient. We ran separate models for each diagnostic category and for each type of payment comparing average per capita primary care payments for those with and without the disorder.

We measured the relative distribution of primary care investment as the ratio of average per capita primary care payments for people with a condition compared to those without the condition. We measured change in the distribution by comparing the ratios at the beginning (2002/03) and end (2011/12) of the study period. We then estimated the change in this distribution by calculating stratum-specific ratios of the total payment ratios from the end and beginning of the study period. If the relative distribution of funding had been consistent over the study period, this ratio would equal 1 . A ratio greater than 1 indicates a relatively higher proportion of funding going to those with the condition over the study period, and a ratio less than 1 indicates a relatively smaller proportion of funding going to those with the condition. We subsequently examined the contribution of payments for urine drug testing for people who received opioid substitution therapy.

We carried out all analyses using SAS 9.4 (SAS Institute).

\section{Sensitivity analysis}

We conducted a sensitivity analysis to assess the impact of clustering by patient or physician.

\section{Ethics approval}

The study was approved by the Queen's University Health Sciences Research Ethics Board and the Sunnybrook Health Sciences Centre Research Ethics Board.

\section{Results}

We identified 1645324 Ontario adults in 2011/12 (16.6\% of the adult population) with a mental health disorder, including 149185 with psychotic disorders, 1456981 with nonpsychotic disorders, and 127820 with substance use disorders (Table 1). People with a mental health disorder were more likely to be female, poor and nonimmigrant, to live in urban settings and to have 2 or more comorbid conditions. Similar patterns were seen for people with psychotic and nonpsychotic disorders. Those with substance use disorders were more likely to be young and male, and less likely to live in urban settings. We found similar patterns in 2002/03 except for a higher prevalence of any mental health disorder $(20.0 \%)$ (data not shown).

Total per capita primary care payments increased by $88.3 \%$ over the study period (Table 2 ). Total primary care payments for any mental health disorder were higher than for the general population at baseline and study end. However, growth was slower for those with any mental health disorder $(62.0 \%)$, psychotic disorders $(45.3 \%)$ and nonpsychotic disorders $(50.2 \%)$, whereas total primary care payments grew more rapidly for those with substance use disorders (142.7\%). In $2011 / 12,45.5 \%$ of primary care payments for the general population went to alternative funding payments, which was higher than the corresponding figure for any mental health disorder $(28.0 \%)$ and each subcategory (psychotic disorders $25.8 \%$, nonpsychotic disorders $31.5 \%$ and substance use disorders $11.3 \%$ ).

Results were similar in the adjusted model (Table 3 ). Overall payments for people with any mental health disorder were $50 \%$ higher than for those without a mental health disorder in $2002 / 03$, but by $2011 / 12$ they were $35 \%$ higher, a $10 \%$ relative reduction. Overall payments were also reduced for psychotic disorders (by 8\%) and nonpsychotic disorders (by $13 \%$ ), but increased by $141 \%$ for substance use disorders. A similar relative payment reduction was seen for diabetes (6\%). Total alternative funding payments were directed less or about equally to those with and without mental health disorders (ratios for specific conditions 0.82-1.05) and diabetes (ratio 1.17).

In the sensitivity analysis, although we found evidence of physician clustering, neither the point estimates nor the ratios changed significantly when we adjusted for clustering.

We examined the contribution of urine drug testing for people who received opioid substitution to the increased FFS payments for people with substance use disorders. The mean per person payment for urine drug testing increased from $\$ 0$ in 2002/03 to $\$ 1140$ for the 115778 people who underwent testing in 2011/12, accounting for the majority of the increase in FFS payments.

\section{Interpretation}

We found that, during a period of substantial reform in primary care delivery and growth in primary care funding in Ontario, new investment flowed inequitably to the care of adults with mental health disorders. There was slower overall growth in primary care funding for those with mental health disorders than for the general population and relatively lower alternative funding payments than expected based on need. The exception was in payments for substance use disorders, where there was substantial overall growth in total payments, driven by large increases in FFS payments (led by the need 
Table 1: Ontario adult population with mental health disorders and diabetes mellitus by sex, age, neighbourhood income quintile, rurality, immigrant status and comorbidity, 2011/12

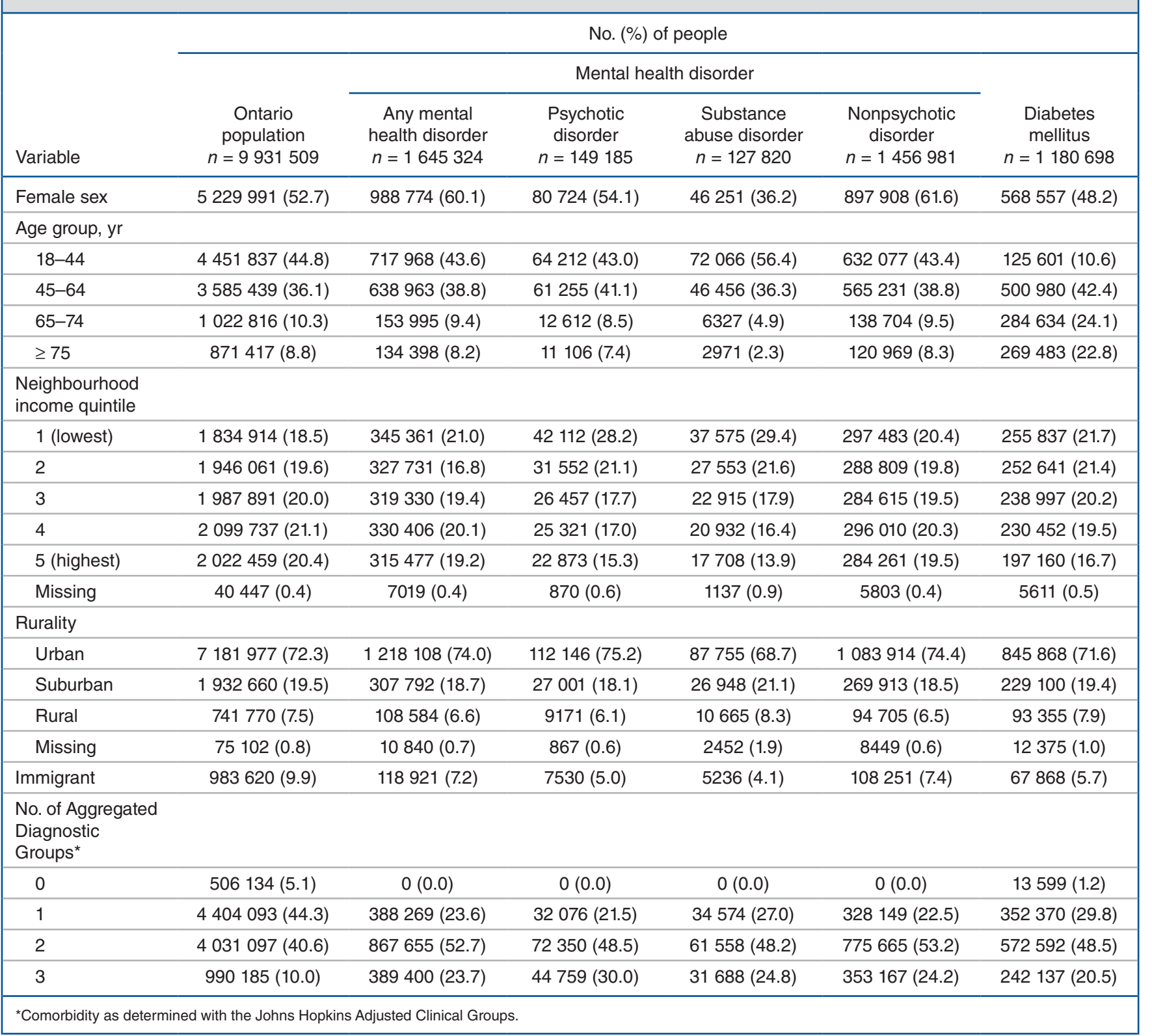

for frequent urine drug testing for opioid substitution therapy) and smaller investment in alternative funding payments.

Our findings can be expected based on the voluntary nature and self-selection of physicians into new payment models and the nature of new incentives. ${ }^{26}$ In blended capitation models, physicians receive a monthly payment for providing an essential basket of services for each enrolled patient, adjusted for age and sex but not case-mix. People with mental health disorders have complex health needs ${ }^{27}$ and may be underserved in a structure with disincentives to enrol such patients. Previous work showed underrepresentation of people with mental health disorders in new models of primary care delivery ${ }^{16}$ and fewer primary care visits related to mental health in capitation-based models. ${ }^{28}$ Despite incentives to provide care to people with schizophrenia and bipolar disorder (up to $\$ 2000$ annually to physicians caring for at least 10 patients with either diagnosis), there was a relative decrease in payments for mental health disorders (other than substance use) under primary care reform in Ontario.

The large increase in primary care payments for people with substance use disorder is appropriate given the opioid crisis. ${ }^{29}$ Urine testing for opioid substitution represented a substantial proportion of primary care costs for people with substance use disorder. Relatively low alternative funding payments are also consistent with reform incentives. Physicians in new models are eligible for an access bonus when their team provides all primary care services. Patients receiving opioid substitution at addiction clinics require frequent visits and 


\begin{tabular}{|c|c|c|c|c|c|c|c|c|c|}
\hline \multirow[b]{3}{*}{ Subgroup } & \multicolumn{8}{|c|}{ Average per capita PCP, \$ } & \multirow{3}{*}{$\begin{array}{l}\% \text { change in } \\
\text { average per } \\
\text { capita PCP } \\
2002 / 03 \text { to } \\
2011 / 12 \ddagger\end{array}$} \\
\hline & \multirow[b]{2}{*}{$\begin{array}{l}\text { Overall, } \\
\text { 2002/03* }\end{array}$} & \multicolumn{6}{|c|}{ Funding model } & \multirow[b]{2}{*}{$\begin{array}{l}\text { Overall, } \\
2011 / 12\end{array}$} & \\
\hline & & $\begin{array}{l}\text { Fee-for- } \\
\text { service }\end{array}$ & $\begin{array}{l}\text { Physician } \\
\text { capitation† }\end{array}$ & $\begin{array}{l}\text { Physician } \\
\text { othert }\end{array}$ & $\begin{array}{c}\text { Interdisciplinary } \\
\text { team† }\end{array}$ & Other† & $\begin{array}{l}\text { Total }(\% \text { of } \\
\text { payments) }\end{array}$ & & \\
\hline $\begin{array}{l}\text { Total Ontario } \\
\text { population }\end{array}$ & 173 & 178 & 98 & 28 & 16 & 7 & $148(46)$ & 326 & 88.3 \\
\hline $\begin{array}{l}\text { Any mental health } \\
\text { disorder }\end{array}$ & 321 & 376 & 93 & 30 & 15 & 7 & $145(28)$ & 521 & 62.0 \\
\hline Psychotic disorder & 420 & 453 & 94 & 32 & 21 & 11 & $157(26)$ & 610 & 45.3 \\
\hline $\begin{array}{l}\text { Substance use } \\
\text { disorder }\end{array}$ & 460 & 992 & 66 & 30 & 21 & 10 & $126(11)$ & 1118 & 142.7 \\
\hline $\begin{array}{l}\text { Nonpsychotic } \\
\text { disorder }\end{array}$ & 308 & 317 & 95 & 29 & 14 & 7 & $145(32)$ & 462 & 50.2 \\
\hline Diabetes mellitus & 292 & 304 & 125 & 49 & 15 & 7 & $196(39)$ & 500 & 71.2 \\
\hline \multicolumn{10}{|c|}{$\begin{array}{l}\text { Note: } P C P=\text { primary care payment. } \\
{ }^{*} \text { Fee-for-service only. } \\
\text { †Alternative funding. } \\
\text { fDifferences are due to rounding. }\end{array}$} \\
\hline
\end{tabular}

\begin{tabular}{|c|c|c|c|c|c|c|c|c|c|c|c|c|c|c|c|c|c|}
\hline \multirow[b]{4}{*}{ Subgroup } & \multicolumn{16}{|c|}{ Adjusted per capita PCP estimate, $\$$, and ratio of payment estimate for those with and without each condition* } & \multirow{4}{*}{$\begin{array}{c}\text { Ratio of } \\
\text { overall } \\
\text { adjusted } \\
\text { payment } \\
\text { ratios } 2011 / 12 \\
\text { and 2002/03 }\end{array}$} \\
\hline & \multirow{2}{*}{\multicolumn{2}{|c|}{$\begin{array}{l}\text { Overall, } \\
2002 / 03 \dagger\end{array}$}} & \multicolumn{12}{|c|}{ Funding model, 2011/12 } & \multirow{2}{*}{\multicolumn{2}{|c|}{$\begin{array}{l}\text { Overall, } \\
2011 / 12\end{array}$}} & \\
\hline & & & \multicolumn{2}{|c|}{$\begin{array}{l}\text { Fee-for- } \\
\text { service }\end{array}$} & \multicolumn{2}{|c|}{$\begin{array}{l}\text { Physician } \\
\text { capitation } \ddagger\end{array}$} & \multicolumn{2}{|c|}{$\begin{array}{l}\text { Physician } \\
\text { otherł }\end{array}$} & \multicolumn{2}{|c|}{$\begin{array}{l}\text { Interdisciplinary } \\
\text { team‡ }\end{array}$} & \multicolumn{2}{|c|}{ Otherł } & \multicolumn{2}{|c|}{ Totalł } & & & \\
\hline & Cost & Ratio & Cost & Ratio & Cost & Ratio & Cost & Ratio & Cost & Ratio & Cost & Ratio & Cost & Ratio & Cost & Ratio & \\
\hline $\begin{array}{l}\text { Any mental } \\
\text { health disorder }\end{array}$ & 301 & 1.50 & 387 & 1.45 & 130 & 0.95 & 82 & 1.08 & 93 & 0.98 & 73 & 1.16 & 364 & 0.99 & 677 & 1.35 & 0.90 \\
\hline $\begin{array}{l}\text { Psychotic } \\
\text { disorder }\end{array}$ & 304 & 1.38 & 380 & 1.33 & 141 & 1.04 & 83 & 1.08 & 116 & 1.23 & 86 & 1.34 & 387 & 1.05 & 673 & 1.27 & 0.92 \\
\hline $\begin{array}{l}\text { Substance } \\
\text { abuse disorder }\end{array}$ & 355. & 1.62 & 790 & 2.82 & 124 & 0.92 & 73 & 0.94 & 106 & 1.13 & 81 & 1.27 & 305 & 0.82 & 1193 & 2.29 & 1.41 \\
\hline $\begin{array}{l}\text { Nonpsychotic } \\
\text { disorder }\end{array}$ & 304 & 1.50 & 377 & 1.38 & 129 & 0.95 & 82 & 1.08 & 91 & 0.96 & 72 & 1.15 & 366 & 0.99 & 665 & 1.31 & 0.87 \\
\hline $\begin{array}{l}\text { Diabetes } \\
\text { mellitus }\end{array}$ & 282 & 1.34 & 378 & 1.43 & 133 & 0.98 & 106 & 1.53 & 90 & 0.94 & 63 & 0.98 & 417 & 1.17 & 637 & 1.26 & 0.94 \\
\hline
\end{tabular}

urine testing. The loss of the access bonus incentivizes physicians in new models to unenrol these patients and provide care on an FFS basis. The implications for quality of care are unknown, but people with substance use disorders have complex needs and are at elevated risk for chronic diseases, ${ }^{30}$ mental health conditions $s^{31-33}$ and failure to receive preventive health care such as cancer screening, ${ }^{9}$ for which a medical home model may be more appropriate.

System-level barriers to primary care for people with mental health disorders are seen internationally. In the United
States, payment systems frequently compartmentalize primary care and behavioural health delivery, resulting in fragmented and suboptimal care for both behavioural and medical health needs. ${ }^{34}$ Despite lower uninsured status rates, ${ }^{35}$ structural barriers maintain the siloed nature of care. ${ }^{36-39}$ The UK qualityimprovement incentive program has been associated with increased primary care consultation for people with serious mental illness, ${ }^{4}$ but the impact on access for people with other mental health disorders is unknown. In Australia, the Better Access initiative resulted in more frequent visits for depression, 
but concerns persist regarding access for people with schizophrenia and bipolar disorder. ${ }^{40}$ Promising innovations such as medical homes ${ }^{41}$ coordinated care models, ${ }^{42}$ co-location with social services ${ }^{43}$ and emergency department navigators ${ }^{44}$ will require appropriately aligned payment models.

\section{Limitations}

Although this study has strengths, including the populationbased approach to primary care payments over time, it also has limitations. The validated algorithm for detection of mental health and substance use disorders has very good sensitivity and excellent specificity but may have failed to identify some affected people. We identified costs by extending an established patient-level cost allocation method ${ }^{18}$ to include premiums and infrastructure payments specific to Ontario primary care. This approach has not been validated.

Alternative funding payments may appear in multiple databases and may be paid to individual physicians, teams or academic departments. We divided block payments allocated to groups evenly among all group members, because more detailed allocation data were unavailable. About $2 \%$ of all primary care payments could not be allocated for 1 of 3 reasons: the payment was made to a physician with no assigned patients, the payment was made for a service provided to a patient who could not be assigned to a physician, or the payment was made to a group for whom no affiliated physicians could be identified because the group was not in the Corporate Provider Database. Payments to the small number of physicians in older alternative payment models in 2002/03 were not tracked in electronic databases and could not be included. However, nearly all payments were allocated, and the approach was consistent over the study period. Complete payment data were available only until 2012; however, there have since been no major changes in primary care payment models.

\section{Conclusion}

New resources were inequitably allocated to people with mental health disorders during a period of major reform of primary care delivery and payment in Ontario. Future policy directions should address the need for case-mix adjustment and misaligned incentives, monitoring reforms for their impact on high-needs populations and making appropriate adjustments.

\section{References}

1. Table 1: Rates of selected mental or substance use disorders, lifetime and 12 month, Canada, household population 15 and older, 2012. Ottawa: Statistics Canada; 2012. Available: https://www150.statcan.gc.ca/n1/pub/82-624-x/2013001/article/tbl/ tbl1-eng.htm (accessed 2019 Dec. 23).

2. Whiteford HA, Degenhardt L, Rehm J, et al. Global burden of disease attributable to mental and substance use disorders: findings from the Global Burden of Disease Study 2010. Lancet 2013;382:1575-86.

3. Planner C, Gask L, Reilly S. Serious mental illness and the role of primary care. Curr Psychiatry Rep 2014;16:458.

4. Kontopantelis E, Olier I, Planner C, et al. Primary care consultation rates among people with and without severe mental illness: a UK cohort study using the Clinical Practice Research Datalink. BM7 Open 2015;5:e008650.

5. Bradford DW, Kim MM, Braxton LE, et al. Access to medical care among persons with psychotic and major affective disorders. Psychiatr Serv 2008;59: 847-52.

6. Ross LE, Vigod S, Wishart J, et al. Barriers and facilitators to primary care for people with mental health and/or substance use issues: a qualitative study. $B M C$ Fam Pract 2015;16:135.
7. Kurdyak P, Vigod S, Duchen R, et al. Diabetes quality of care and outcomes: comparison of individuals with and without schizophrenia. Gen Hosp Psychiatry 2017;46:7-13

8. Aggarwal A, Pandurangi A, Smith W. Disparities in breast and cervical cancer screening in women with mental illness: a systematic literature review. Am 7 Prev Med 2013;44:392-8.

9. Lasser KE, Kim TW, Alford DP, et al. Is unhealthy substance use associated with failure to receive cancer screening and flu vaccination? A retrospective cross-sectional study. BM7 Open 2011;1:e000046.

10. Starfield B, Shi L, Macinko J. Contribution of primary care to health systems and health. Milbank Q 2005;83:457-502.

11. Starfield B, Shi L. Policy relevant determinants of health: an international perspective. Health Policy 2002;60:201-18.

12. Starfield B. Toward international primary care reform. CMAf 2009;180: 1091-2.

13. Hutchison B, Glazier RH. Ontario's primary care reforms have transformed the local care landscape, but a plan is needed for ongoing improvement. Health Aff (Millwood) 2013;32:695-703.

14. Kiran T, Kopp A, Glazier RH. Those left behind from voluntary medical home reforms in Ontario, Canada. Ann Fam Med 2016;14:517-25.

15. Rudoler D, Laporte A, Barnsley J, et al. Paying for primary care: a crosssectional analysis of cost and morbidity distributions across primary care payment models in Ontario Canada. Soc Sci Med 2015;124:18-28.

16. Steele LS, Durbin A, Sibley LM, et al. Inclusion of persons with mental illness in patient-centred medical homes: cross-sectional findings from Ontario, Canada. Open Med 2013;7:e9-20.

17. Glazier RH, Hutchison B, Kopp A. Comparison of Family Health Teams to other Ontario primary care models, 2004/05 to 2011/12. Toronto: Institute for Clinical Evaluative Sciences; 2015.

18. Wodchis W, Bushmeneva K, Nikitovic M, et al. Guidelines on person-level costing using administrative databases in Ontario. Toronto: University of Toronto; 2013.

19. Steele LS, Glazier RH, Lin E, et al. Using administrative data to measure ambulatory mental health service provision in primary care. Med Care 2004;42: 960-5.

20. MHASEF Research Team. Mental health and addictions system performance in Ontario: a baseline scorecard. Technical appendix. Toronto: ICES; 2018.

21. Hux JE, Ivis F, Flintoft V, et al. Diabetes in Ontario: determination of prevalence and incidence using a validated administrative data algorithm. Diabetes Care 2002;25:512-6.

22. Kralji B. Measuring rurality - RIO2008 BASIC: methodology and results. Toronto: Ontario Medical Association; 2009.

23. Postal code ${ }^{O M}$ conversion file (PCCF), reference guide. Ottawa: Statistics Canada; 2013.

24. Selected demographic, cultural, educational, labour force and income characteristics, mother tongue, age groups and sex for the population of Canada, provinces, territories, census divisions and census subdivisions, 2006 census - 20\% sample data. Ottawa: Statistics Canada; 2006. Available: https://www12.statcan.gc.ca/census -recensement/2006/dp-pd/tbt/Rp-eng.cfm?LANG=E\&APATH=3\&DETAIL $=0 \& \mathrm{DIM}=0 \& \mathrm{FL}=\mathrm{A} \& \mathrm{FREE}=0 \& \mathrm{GC}=0 \& \mathrm{GID}=0 \& \mathrm{GK}=0 \& \mathrm{GRP}=1 \& \mathrm{PID}=9901$ $5 \& \mathrm{PRID}=0 \& \mathrm{PTYPE}=88971,97154 \& \mathrm{~S}=0 \&$ SHOWALL $=0 \&$ SUB $=0 \&$ Temporal $=2006 \&$ THEME $=70 \& \mathrm{VID}=0 \& \mathrm{VNAMEE}=\& \mathrm{VNAMEF}=($ accessed 2019 Aug. 21).

25. Clifford D, Cressie N, England JR, et al. Correction factors for unbiased, efficient estimation and prediction of biomass from log-log allometric models. Forest Ecol Manage 2013;310:375-81.

26. Sibley LM, Glazier RH. Evaluation of the equity of age-sex adjusted primary care capitation payments in Ontario, Canada. Health Policy 2012;104:186-92.

27. Graham K, Cheng J, Bernards S, et al. How much do mental health and substance use/addiction affect use of general medical services? Extent of use, reason for use, and associated costs. Can 7 Psychiatry 2017;62:48-56.

28. Steele LS, Durbin A, Lin E, et al. Primary care reform and service use by people with serious mental illness in Ontario. Healthc Policy 2014;10:31-45.

29. Gomes T, Mamdani MM, Dhalla IA, et al. The burden of premature opioidrelated mortality. Addiction 2014;109:1482-8.

30. Wu LT, Zhu H, Ghitza UE. Multicomorbidity of chronic diseases and substance use disorders and their association with hospitalization: results from electronic health records data. Drug Alcohol Depend 2018;192:316-23.

31. Conway KP, Compton W, Stinson F, et al. Lifetime comorbidity of DSM-IV mood and anxiety disorders and specific drug use disorders: results from the National Epidemiologic Survey on Alcohol and Related Conditions. 7 Clin Psychiatry 2006;67:247-57.

32. Hartz SM, Pato CN, Medeiros H, et al. Comorbidity of severe psychotic disorders with measures of substance use. 7AMA Psychiatry 2014;71:248-54.

33. De Alwis D, Lynskey MT, Reiersen AM, et al. Attention-deficit/hyperactivity disorder subtypes and substance use and use disorders in NESARC. Addict Behav 2014;39:1278-85.

34. Kathol RG, Butler M, McAlpine DD, et al. Barriers to physical and mental condition integrated service delivery. Psychosom Med 2010;72:511-8.

35. Saloner B, Bandara S, Bachhuber $M$, et al. Insurance coverage and treatment use under the affordable care act among adults with mental and substance use disorders. Psychiatr Serv 2017;68:542-8.

36. Maust DT, Oslin DW, Marcus SC. Mental health care in the accountable care organization. Psychiatr Serv 2013;64:908-10. 
37. Kroenke K, Unutzer J. Closing the false divide: sustainable approaches to integrating mental health services into primary care. 7 Gen Intern Med 2017;32: 404-10.

38. Kathol RG, Patel K, Sacks L, et al. The role of behavioral health services in accountable care organizations. Am 7 Manag Care 2015;21:e95-8.

39. Huang $\mathrm{H}$, Meller $\mathrm{W}$, Kishi $\mathrm{Y}$, et al. What is integrated care? Int Rev Psychiatry 2014;26:620-8

40. Farrer LM, Walker J, Harrison C, et al. Primary care access for mental illness in Australia: patterns of access to general practice from 2006 to 2016. PLoS One 2018;13:e0198400.

41. Domino ME, Kilany M, Wells R, et al. Through the looking glass: estimating effects of medical homes for people with severe mental illness. Health Serv Res 2017;52:1858-80.

42. Lagisetty P, Klasa K, Bush C, et al. Primary care models for treating opioid use disorders: What actually works? A systematic review. PLoS One 2017;12: $\mathrm{e} 0186315$.

43. McGuire J, Gelberg L, Blue-Howells J, et al. Access to primary care for homeless veterans with serious mental illness or substance abuse: a follow-up evaluation of co-located primary care and homeless social services. Adm Policy Ment Health 2009;36:255-64.

44. Griswold KS, Homish GG, Pastore PA, et al. A randomized trial: Are care navigators effective in connecting patients to primary care after psychiatric crisis? Community Ment Health 7 2010;46:398-402.

Affiliations: Department of Family Medicine (Bayoumi), Queen's University, Kingston, Ont.; ICES (Bayoumi, Schultz, Glazier); Department of Family and Community Medicine (Glazier), University of Toronto; Department of Family and Community Medicine (Glazier), St. Michael's Hospital, Toronto, Ont.

Contributors: Richard Glazier supervised the work. Imaan Bayoumi and Richard Glazier conceived the study, and Susan Schultz and Richard Glazier designed it. Susan Schultz analyzed the data. Imaan Bayoumi drafted the manuscript. All of the authors interpreted the data, revised the manuscript critically for important intellectual content, approved the final version to be published and agreed to be accountable for all aspects of the work.
Funding: Funding for this project was provided by the Transdisciplinary Understanding and Training on Research-Primary Health Care Ontario Alumni Fellowship, through Innovations Strengthening Primary Healthcare through Research. Innovations Strengthening Primary Healthcare through Research is a research centre supported by the Ontario Strategy for Patient-Oriented Research (SPOR) SUPPORT Unit, which is jointly funded by the Government of Ontario and the Canadian Institutes of Health Research. The project was also supported by ICES, which is funded by an annual grant from the Ontario Ministry of Health and Long-Term Care. Richard Glazier was supported as a Clinician Scientist by the Department of Family and Community Medicine at St. Michael's Hospital and at the University of Toronto.

Prior presentation: This work was presented at the North American Primary Care Research Group annual conference, Nov. 9-13, 2018, Chicago, Ill.

Data sharing: The data set from this study is held securely in coded form at ICES. Although data-sharing agreements prohibit ICES from making the data set publicly available, access can be granted to those who meet prespecified criteria for confidential access, available at www.ices.on.ca/ DAS. The full data set creation plan and underlying analytic code are available from the authors on request, with the understanding that the programs may rely on coding templates or macros that are unique to ICES and are therefore inaccessible or may require modification.

Disclaimer: This study was supported by ICES, which is funded by an annual grant from the Ontario Ministry of Health and Long-Term Care (MOHLTC). The opinions, results and conclusions reported in this article are those of the authors and are independent from the funding sources. No endorsement by ICES, the Ontario MOHLTC or Innovations Strengthening Primary Healthcare through Research is intended or should be inferred.

Supplemental information: For reviewer comments and the original submission of this manuscript, please see www.cmajopen.ca/content/8/2/ E455/suppl/DC1. 